\title{
Trajectory Control During an Aeroassisted Maneuver Between Coplanar Circular Orbits
}

\author{
Willer Gomes dos Santos ${ }^{1}$ Evandro Marconi Rocco, Valdemir Carrara ${ }^{1}$
}

\begin{abstract}
This paper presents the simulation results of an aeroassisted maneuver around the Earth, between coplanar circular orbits, from a geostationary orbit to a low orbit. The simulator developed considers a reference trajectory and a trajectory perturbed by external disturbances combined with non-idealities of sensors and actuators. It is able to operate in closed loop, controlling the trajectory (drag-free control) at each instant of time using a Proportional-Integral-Derivative (PID) controller and propulsive jets. We adopted a spacecraft with a cubic body composed of two rectangular plates arranged perpendicular to the velocity vector of the vehicle. Propulsive jets are applied at the apogee of the transfer orbit in order to keep the perigee altitude and control the rate of heat transfer suffered by the vehicle during atmospheric passage. A PID controller is used to correct the deviation in the state vector and in the keplerian elements. The U.S. Standard Atmosphere is adopted as the atmospheric model. The results have shown that the aeroassisted transfer presents a smaller fuel consumption when compared to a Hohmann transfer or a bi-elliptic transfer.
\end{abstract}

KEYWORDS: Aeroassisted maneuvers, Orbital dynamic, Trajectory control.

\section{INTRODUCTION}

An orbital maneuver is the transfer of a satellite from one orbit to another by means of a change in velocity. To perform this change, the spacecraft has to engage the thrusters or use the natural forces of the environment. The Hohmann transfer and the bi-elliptic transfer are some alternatives to perform an orbital maneuver by propulsive means. In 1961, Howard London presented the approach of using aerodynamic forces to change the trajectory and velocity of a spacecraft, this new technique became known as aeroassisted maneuvers (Walberg, 1985). This type of orbital transfer can be accomplished in several layers of the atmosphere. The altitude reached by vehicle is linked to the mission's purpose and to the maximum thermal load supported by the vehicle structure. The main advantage of this type of maneuver is the fuel economy. According to Walberg (1985), many papers on aeroassisted orbital transfer have been made in recent decades and it has been shown that a significant reduction in fuel can be achieved using aeroassisted maneuvers instead of Hohmann transfer. Consequently, the reduction of fuel provides an increase in the payload capacity of the vehicle.

Orbit transfer between two circular and coplanar orbits is very common. The technique of using atmospheric drag to reduce the semi-major axis is known as aerobraking and it was first used on March $19^{\text {th }}, 1991$, by spacecraft Hiten. The launch was conducted by the Institute of Space and Astronautical Science of Japan (ISAS). The spacecraft passed through Earth's atmosphere at an altitude of $125.5 \mathrm{~km}$ over the Pacific Ocean at a speed of $11 \mathrm{~km} / \mathrm{s}$. The experience resulted in a decrease in apogee altitude of 8,665 km. In May 1993, an aerobraking maneuver was used on a mission to Venus by Magellan spacecraft, whose goal was to circularize the orbit of the spacecraft. In 1997, the probe U.S. Mars Global Surveyor (MGS) 
used its solar panels as "wings" to control its passage through the tenuous upper atmosphere of Mars and lower its apoapsis.

There are several missions requirements that become feasible with the use of aeroassisted vehicles, as for example, to reconfigure orbital systems that are unable to perform an orbital maneuvering (such as replacing a malfunctioning satellite by a spare), to transfer space debris to a new orbit, to operate Space Transportation Systems (STS), to use the atmospheric drag as a brake force to provide orbit capturing of the vehicle, to assist the International Space Station with the transfer of cargo between geostationary orbit (GEO) and low earth orbit (LEO), among others.

Within the context of this paper, we can cite the scientific micro-satellite Franco-Brazilian (FBM) project, in partnership between the Brazilian and French space agencies (INPE and CNES), which would be released as piggy-back on an Ariane 5, and then would perform aerobraking maneuvers to transfer the satellite to the orbit service (Furlan, 1998). The Ariane 5 rocket has the capacity to carry up to eight microsatellites with a maximum individual weight of $120 \mathrm{~kg}$ through the Ariane Structure for Auxiliary Payload (ASAP). However, the rocket was designed to place satellites in geostationary transfer orbits. The propellant required to transfer the FBM to a low orbit (between 800 and $1,300 \mathrm{~km}$ ) by means of chemical propellants, would exceed the allowed amount of mass. This question has led space agencies to study the concept of aerobraking as a workaround. However, CNES, in 2003, left the program which was subsequently discontinued (Brezun et al., 2000). In another interesting study with the same context, Schulz (2001) developed an optimal control law that minimizes the fuel consumption during an aeroassisted maneuver, as well as analyzed orbital changes.

This paper will present the simulation of an aerobraking maneuver between GEO and low orbit. The study aims at examinining the effects that this kind of maneuver can cause in the orbital elements. It will also demonstrate the difference in fuel costs and the elapsed transfer time between an aeroassisted maneuver and a fully propulsive maneuver. The results show that the aeroassisted transfer has a propellant consumption lower than a Hohmann or a bi-elliptic transfer.

\section{PROBLEM DEFINITION}

In this paper, a spacecraft with a cubic body composed of two rectangular plates was adopted, called aerodynamic plates, placed in opposite sides of the vehicle's body. The inclination angle of the plates, regarding its molecular flow (attack angle), was fixed at 90 degrees, in order to maximize the projected area and the drag force. The spacecraft will be transferred from the GEO to a low orbit. The orbits are considered circular and coplanar. A multipass aeroabraking strategy is used to perform the transfer.

First, the spacecraft applies an impulse to take the vehicle out of the GEO and put it into an elliptical orbit with perigee within the limits of the atmosphere. After each passage at atmospheric region, a reduction of the apogee transfer orbit occurs. When the spacecraft reaches its final apogee altitude, then, a new impulse is applied to the vehicle to remove it from the transfer orbit and insert it into the final orbit. In order to control the rate of heat transfer suffered by the vehicle during the passage through atmosphere, propulsive jets are applied at the apogee, correcting the decay of perigee. This transfer strategy is shown in Fig. 1.

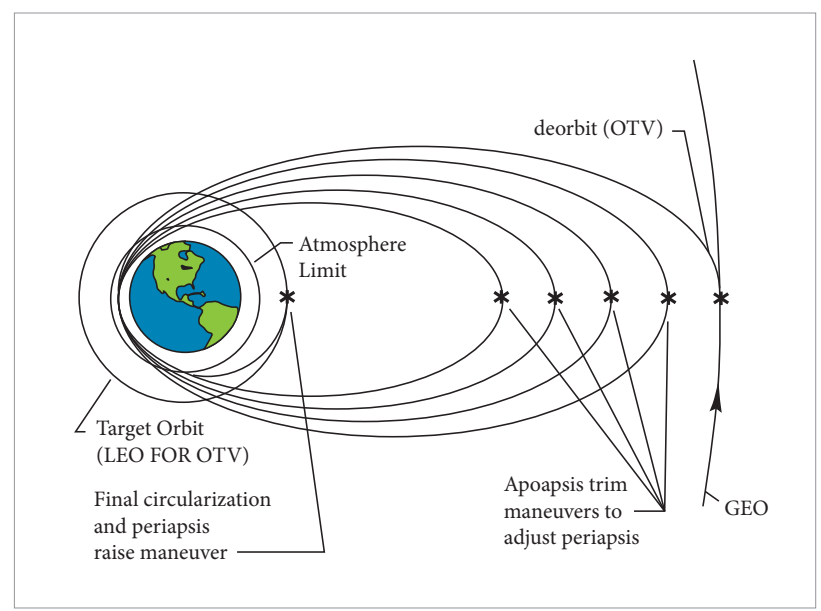

Figure 1. Multipass aerobraking (Walberg, 1985).

In this work, it was used the Aeroassisted Spacecraft Maneuver Simulator (SAMS) based on the Spacecraft Trajectory Simulator (STRS), which uses a drag-free control architecture to control the spacecraft trajectory (Rocco, 2006, 2008, 2009, 2010). Usually, a ground based open loop control is used for maneuver correction and orbit transfer. However, in some drag-free missions (Gravity Probe B, Hipparcos, GOCE, etc) the feedback control is mandatory. The STRS and SAMS consider a reference trajectory and a trajectory perturbed by external disturbances, including the aerodynamic effects, combined with non-idealities 
of sensors and actuators. The simulator works in closed loop controlling the trajectory at each instant of time, which is one of the input parameters, using a Proportional-Integral-Derivative (PID) controller and propulsive jets. Santos (2011) used the SAMS to study how the orbital elements can be changed by an aeroassisted maneuver and how much fuel is saved comparing with a propulsive maneuver. Figure 2 shows a basic diagram of the running logic of the aeroassisted maneuver simulator. In this work, noises and non-idealities in the actuator and in the sensor were not considered.

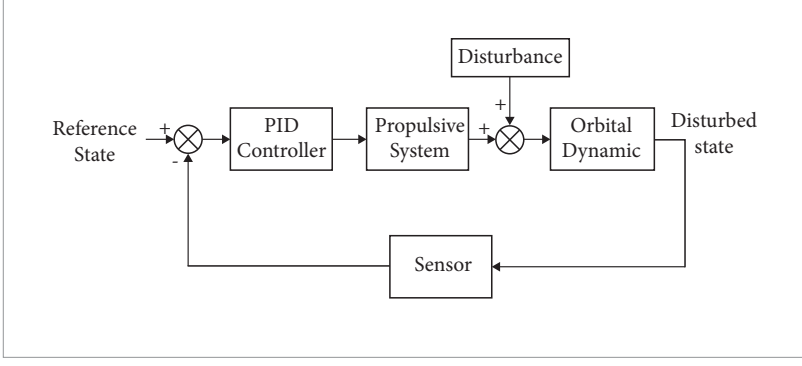

Figure 2. Basic diagram of the aeroassisted maneuver simulator.

\section{BACKGROUND CONCEPTS}

This section aims at presenting the main equations and concepts used in the development of this work. Firstly, the concepts about drag-free technology are presented, and then the equations of aeroassisted maneuver and trajectory control system are introduced.

\section{THE DRAG-FREE SATELLITE}

Drag-free satellites have a payload that follows a geodesic path through space. The satellite is affected by gravity and by non-gravitational forces. The control system for compensation of the non-gravitational forces is called drag-free control system. The drag-free device has an outer shell and an inner mass called proof mass. Inside the outer shell, the proof mass is floating freely and the distance between the outer shell and the proof mass is constantly measured. When a displacement of the proof mass regarding the outer shell is detected, this means that the outer shell has been influenced by non-gravitational forces and it has moved. Hence, thrusters will reposition the outer shell regarding proof mass so that it returns to the initial position.
According to Theil and Silas-Guilherme (2005), drag-free technology is essential for scientific missions which need a very low disturbance environment. Several missions have used this technology, such as Gravity Probe B (GP-B) to test the relativistic effects on a gyroscope; STEP and MICROSCOPE had the objective of testing the weak principle of equivalence; Laser Interferometer Space Antenna (LISA) for the detection of gravitational waves; and Gravity Field and Steady State Ocean Circulation Explorer (GOCE), launched in March 2009, to determine the gravity-field anomalies with high accuracy; among others.

\section{AEROASSISTED MANEUVER}

The main forces acting on a spacecraft in LEO are gravitational force $(m g)$, thrusters force $\left(T_{s}\right)$ and aerodynamic forces $(F)$, caused by the interaction of the satellite with the atmosphere. The spacecraft position in space determines the magnitude of aerodynamic forces suffered by the spacecraft. The higher the planetary atmospheric density is, the stronger the aerodynamic forces are. The aerodynamic force can be divided into two: the drag force $\left(F_{\mathrm{D}}\right)$, whose direction is opposite to the velocity vector, and the lift force $\left(F_{\mathrm{L}}\right)$, perpendicular to the drag force. According to Vinh (1981), the magnitude of these forces is given by the following equations:

$F_{D}=\frac{1}{2} \rho S V^{2} C_{D}$

$F_{L}=\frac{1}{2} \rho S V^{2} C_{L}$

where $r$ is the atmosphere density, $C_{\mathrm{D}}$ and $C_{\mathrm{L}}$ are, respectively, the drag and lift coefficients on the projected area $S$, and $V$ is the velocity of the spacecraft in relation to the atmosphere. The lift can also be decomposed into altitude lift force $\left(F_{\mathrm{A}}\right)$ and lateral lift force $\left(F_{\mathrm{B}}\right)$. The attack angle $(a)$ is measured between the longitudinal axis of the spacecraft and velocity in relation to the atmosphere. The magnitude of the aerodynamic force depends mainly on the attack angle, and its direction varies depending on the bank angle $(s)$ between the lift plane and the plane, formed by the velocity vector in relation to the atmosphere and the vector position of the spacecraft, as shown in Fig. 3.

The direction and amplitude of these forces can be calculated by the following equations (Guedes, 1997):

$\mathbf{F}_{\mathbf{D}}=-F_{D} \hat{\mathbf{V}}$ 


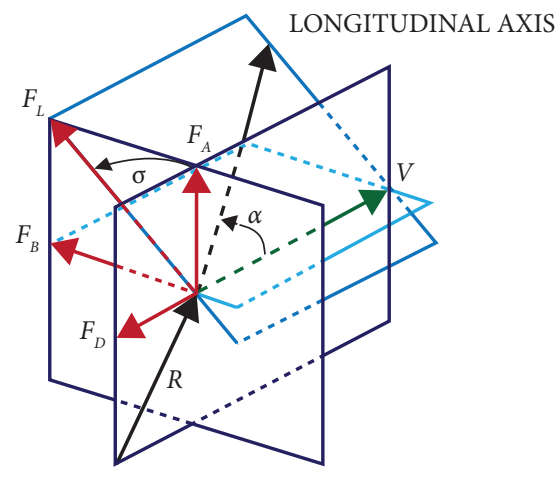

Figure 3. Components of the aerodynamic forces, attack angle and bank angle (Guedes, 1997).

$\mathbf{F}_{\mathbf{L}}=F_{A} \hat{\mathbf{N}}+F_{B} \hat{\mathbf{H}}$

where $\hat{\mathbf{V}}$ is the velocity in relation to the atmosphere versor; $\hat{\mathbf{H}}$ is the angular momentum versor; and $\hat{\mathbf{N}}$ is the altitude versor. The altitude lift force, the lateral lift force, the angular momentum vector and the altitude vector are calculated according to the following equations:

$F_{A}=\frac{1}{2} \rho S V^{2} C_{A}$

$F_{B}=\frac{1}{2} \rho S V^{2} C_{B}$

$H=R \times V$

$N=V \times H$

The drag coefficient $\left(C_{\mathrm{D}}\right)$, altitude lift $\left(C_{\mathrm{A}}\right)$ and lateral lift $\left(C_{\mathrm{B}}\right)$, are calculated using the Impact Method (Regan and Anandakrishnan, 1993), according to the following equations:

$C_{D}=2 \operatorname{sen}^{2} \alpha$

$C_{L}=2 \operatorname{sen} \alpha \cos \alpha$

$C_{A}=C_{L} \cos \sigma$

$C_{B}=C_{L} \operatorname{sen} \sigma$
The Impact Method, or Newtonian Impact Theory (Vinh et al., 1970), is a simplified numerical technique to approximate the forces and torques acting on a body. It assumes an elastic reflection of particles in a specular surface. The normal component of impact velocity is reversed while the tangential component is unchanged. This model assumes that the particles have no random velocity component, usually associated to microscopic particles of gas (Regan and Anandakrishnan, 1993).

The U.S. Standard Atmosphere model provides the value of the atmospheric density, depending on the position of the vehicle, for the calculation of aerodynamic forces. The velocity of the spacecraft in relation to the atmosphere in the inertial system is calculated assuming that the atmosphere has the same rotation velocity of the Earth and its equation is given by Kuga et al. (2008):

$\mathbf{V}=\dot{\mathbf{r}}-\omega \times \mathbf{r}=\left[\begin{array}{c}\dot{x}+\omega y \\ \dot{y}-\omega x \\ \dot{z}\end{array}\right]$

where $\dot{\mathbf{r}}$ is the velocity vector in relation to the inertial system and $\omega$ is the angular velocity vector of Earth's rotation.

Some of the major difficulties faced by the spacecraft during atmospheric maneuver are related to the heating rate and velocity deceleration. These quantities increase when the vehicle is submitted to high atmospheric densities and high velocities. In the upper atmosphere, it should be considered a form of heating known as free molecular heating. This phenomenon occurs due to the impact of free molecules against the vehicle. The rate of heat transfer as per area unit is given by the following equation (Gilmore, 1994):

$\dot{Q}=\frac{1}{2} \alpha_{c} \rho V^{3}$

where $\alpha_{c}$ is the thermal accommodation coefficient (Gilmore (1994) recommends the use of $\alpha_{c}=1$ ).

The orbital spacecraft state is described by the coordinates $\mathrm{X}=[\mathrm{r} \mathrm{V}]$, measured in an inertial frame centered on Earth, and the dynamic model of the spacecraft used in this paper is given by:

$\ddot{\mathbf{r}}=-\frac{\mu}{r^{3}} \mathbf{r}-\frac{1}{2} C_{D} \rho S V \mathbf{V}+\Delta \mathbf{V}_{\mathbf{p}}$

where $\mu$ is the central body gravitational constant (product of the central body mass and the universal gravitational constant) 
and $\Delta \mathrm{V}_{\mathrm{p}}$ is the velocity variation caused by propulsive thrusters when activated. The lift force is null because the attack angle of the aerodynamic plates is perpendicular to the velocity vector.

\section{TRAJECTORY CONTROL SYSTEM}

A PID controller was used to correct the deviation of the spacecraft trajectory. Most of the industrial controllers are PID due to its flexibility, low cost and robustness. The PID control action is computed by:

$c(t)=K_{P} e(t)+K_{I} \int e(t) d t+K_{D} \frac{d e(t)}{d t}$

where $K_{\mathrm{p}}, K_{\mathrm{I}}$ and $K_{\mathrm{D}}$ are the proportional gain, integral gain and derivative gain respectively, and $e(t)$ is the position error. Most control systems today use digital computers. Hence, to implement the PID control law in a digital computer, it is necessary to discretize the PID equation $c(t)$. Several discretization methods can be consulted in Franklin et al. (1998). Using the discretization methodology proposed by Hemerly (2000), we can write the discrete PID control law equation, as

$$
\begin{aligned}
& u(k)=u(k-1)+\left(K_{P}+\frac{K_{D}}{T}+K_{I} T\right) e(k)+ \\
& \left(-K_{P}-2 \frac{K_{D}}{T}\right) e(k-1)-\frac{K_{D}}{T} e(k-2)
\end{aligned}
$$

where $T$ is the sample period.

\section{RESULTS}

This section aims at presenting the results of an aeroassisted maneuver simulation to transfer the spacecraft from a GEO to a low orbit of $1,000 \mathrm{~km}$ of altitude. The presented curves refer only to the aeroassisted transfer. Table 1 shows the initial conditions of the orbit.

The complete maneuver was performed in 58.93 days and, at the end of the period, there was a reduction of approximately $35,000 \mathrm{~km}$ in the apogee altitude, according to Fig. 4 . The perigee altitude remained at an average of $115 \mathrm{~km}$, with a variation of $\pm 0.5 \mathrm{~km}$ due to the application of jet propulsion at the apogee of the orbit, shown in Fig. 5.

There was no change in the orbit inclination because lift forces were not being applied to the vehicle. Figure 6 illustrates

Table 1. Initial condition of the transfer orbit.

\begin{tabular}{|c|c|c|}
\hline Description & Value & Units \\
\hline Apogee altitude & 35786.14 & $\mathrm{~km}$ \\
\hline Perigee altitude & 115 & $\mathrm{~km}$ \\
\hline Eccentricity & 0.7332 & - \\
\hline Inclination & 1 & degrees \\
\hline RAAN & 200 & degrees \\
\hline Perigee argument & 10 & degrees \\
\hline Mean anomaly & 180 & degrees \\
\hline
\end{tabular}

${ }^{\star}$ Right Ascension of Ascending Node.

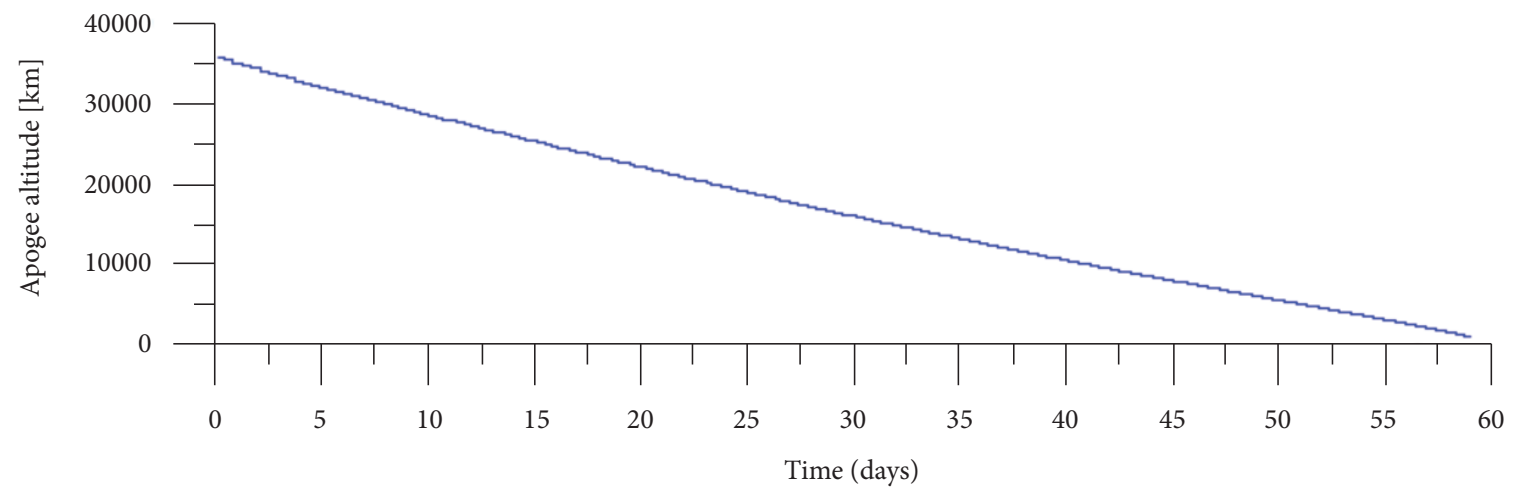

Figure 4. Apogee altitude as function of time. 


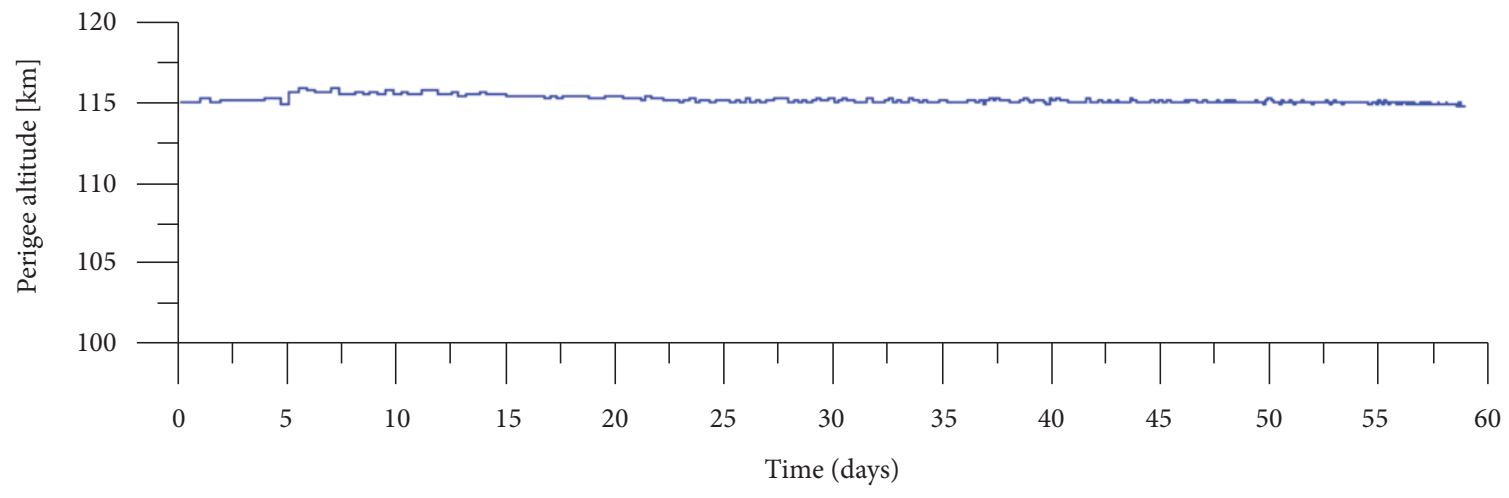

Figure 5. Perigee altitude as function of time.

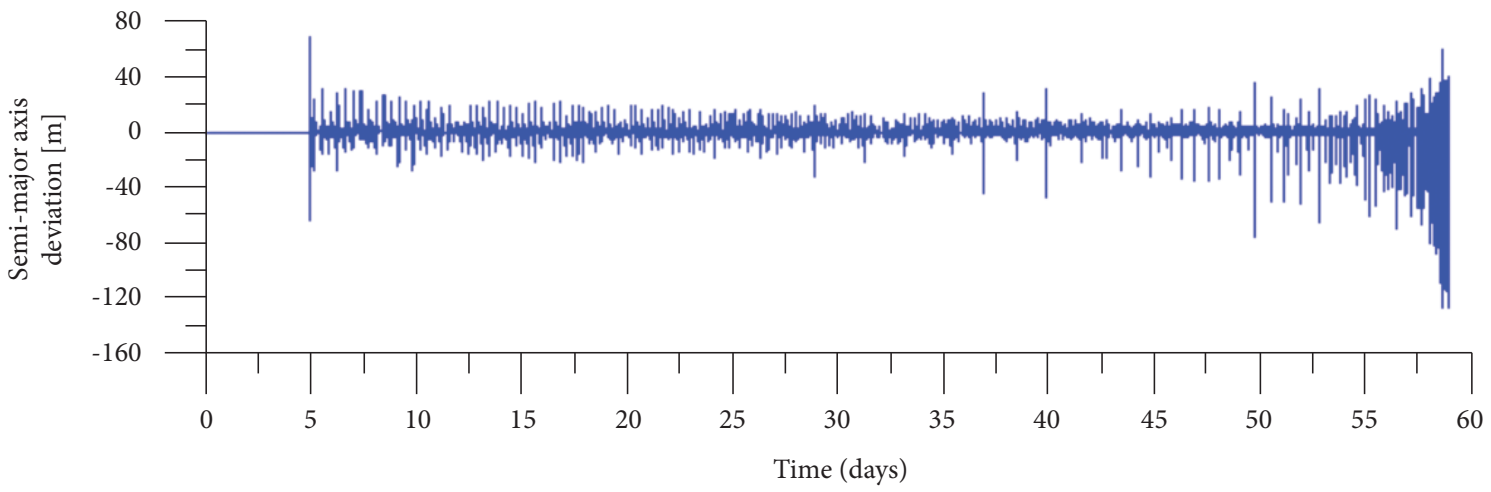

Figure 6. Semi-major axis deviation as function of time.

the deviation of the semi-major axis versus time. During the maneuver, the control system acts to reduce the error between the reference trajectory and the disturbed trajectory. The error appears when the first thrust is applied at the apogee.

Figure 7 shows the variation in the position components $\mathrm{X}$, $\mathrm{Y}$ and $\mathrm{Z}$, for the first five days of maneuvering. The variation is almost zero at the $\mathrm{Z}$ component due to the roughly equatorial orbit. The behavior X and Y components is related to the orbit eccentricity. As the vehicle approaches the perigee the orbital velocity increases, and vice versa.

The applied thrust at the orbit apogee versus time is shown in Fig. 8. Due to orbit circularization the trajectory path inside low atmosphere is increased, causing perigee decay. So, while low thrusters are applied at the beginning of the maneuvering process in order to adjust the trajectory derivations, high impulses are employed at the final orbit to correct the perigee height.

Figure 9 illustrates the drag force suffered by the vehicle along the atmospheric path. It can be observed a downward trend close to the final orbit. This behavior is related to the velocity reduction and with the circularization of the orbit.

The heat transfer rate suffered by the vehicle as function of time is shown in Fig. 10. The maximum value supported by the vehicle depends on the material structure. The values obtained are within the limit given by Kumar and Tewari (2005). However, 

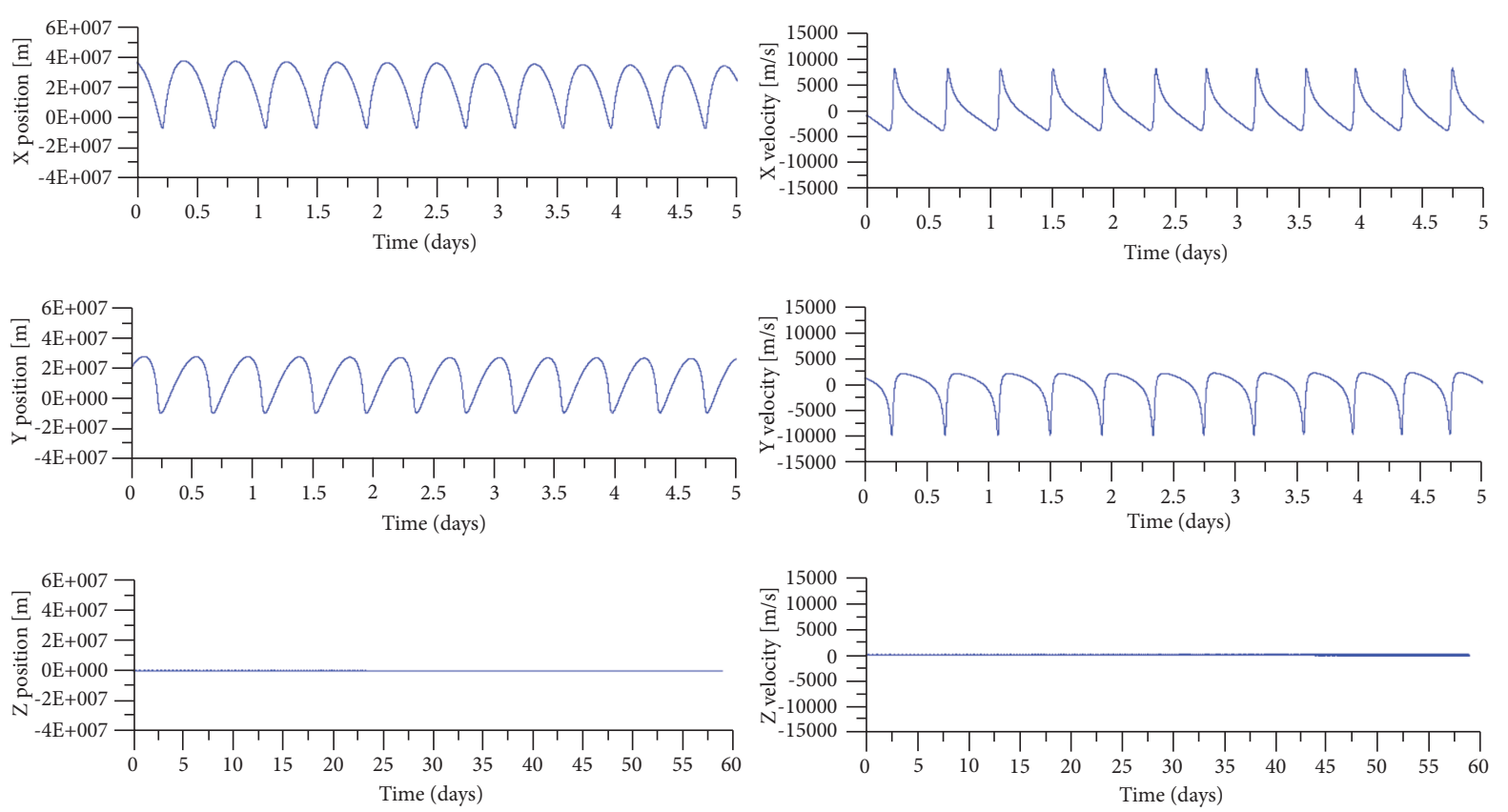

Figure 7. $\mathrm{X}, \mathrm{Y}$ and $\mathrm{Z}$ components of the position and velocity vectors as function of time.

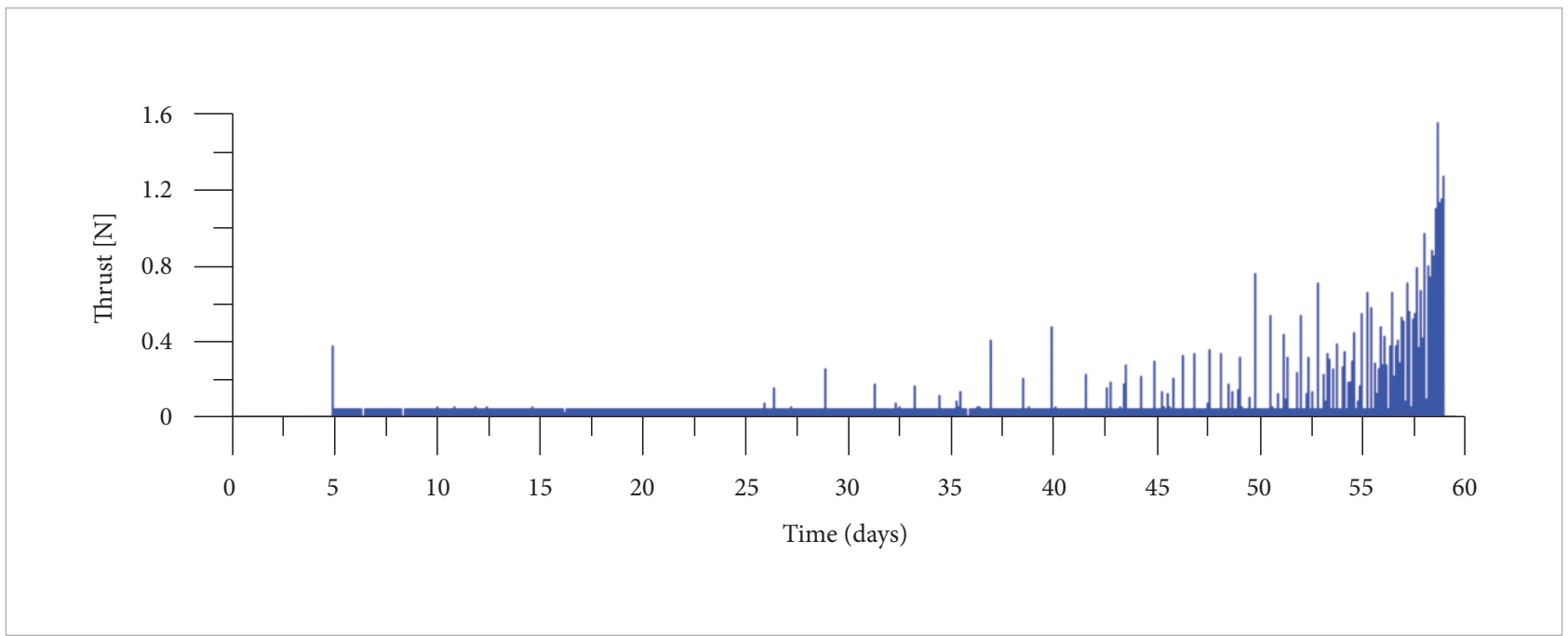

Figure 8. Propulsive thrust as function of time.

the heat rate experienced by the vehicle can be increased or decreased by controlling the perigee altitude; the lower the perigee height, the higher the heat suffered by the vehicle.

Regarding the consumption of propellant, two situations are considered. The first one illustrates a hypothetical situation: it is considered that the drag force suffered by the vehicle is provided by the propulsion system, whose results are presented in Fig. 11; and the second situation (Fig. 12), shows the case that considers only the thrust necessary to correct the perigee altitude.

Simulations show that up to $200 \mathrm{~kg}$ of fuel propellant should be needed in order to perform orbit adjusting using only the propulsion system, with application of thrust at perigee of the orbit 
Gomes dos Santos, W., Rocco, E.M. and Carrara, V.

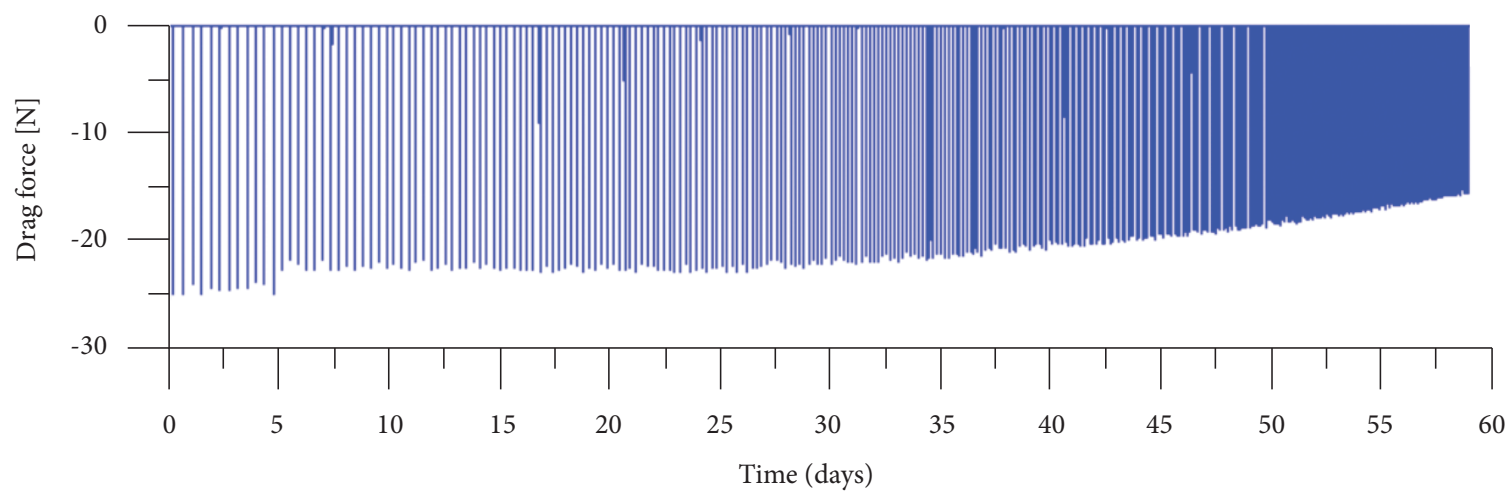

Figure 9. Drag force as function of time.

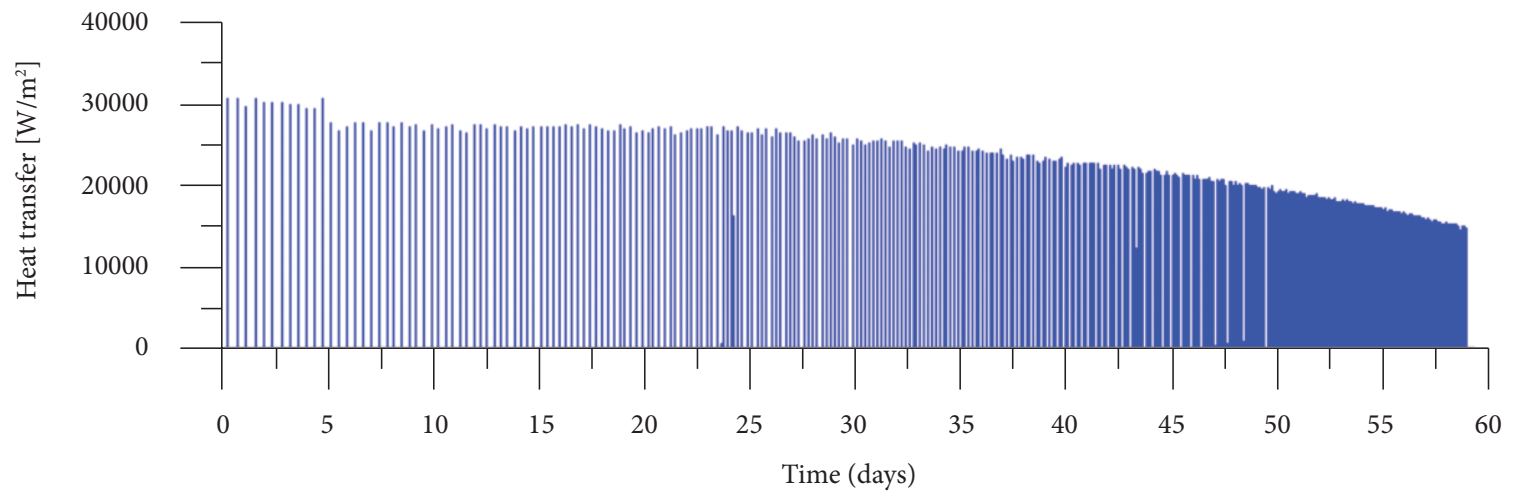

Figure 10. Rate of heat transfer as function of time.

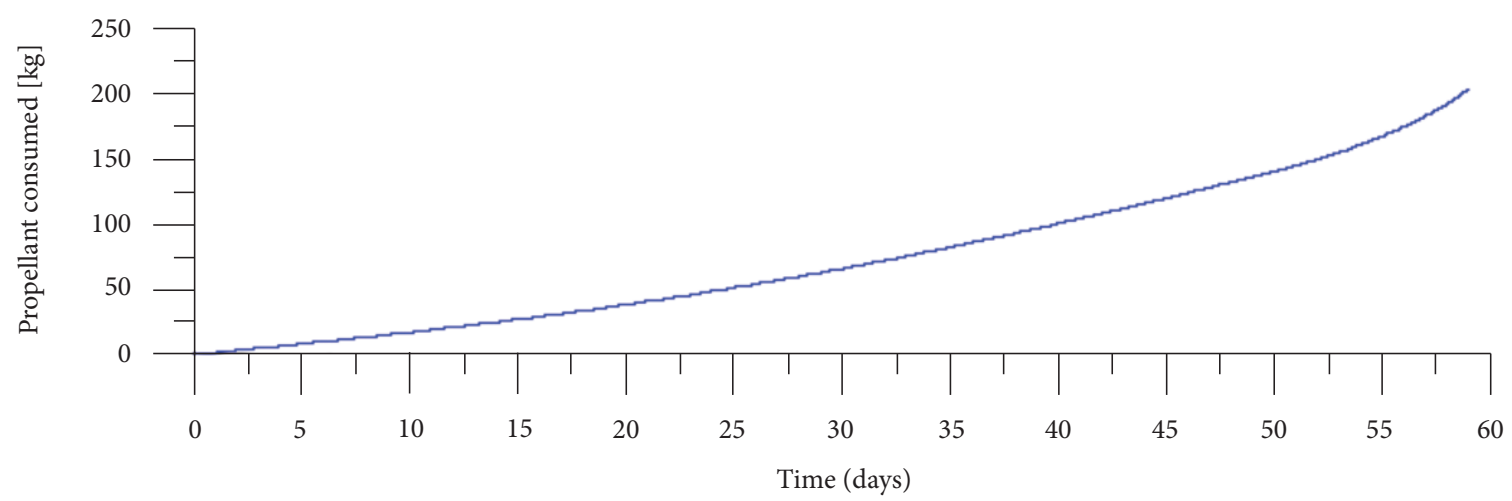

Figure 11. Hypothetical situation: propellant required for applying a thrust equal to drag force. 


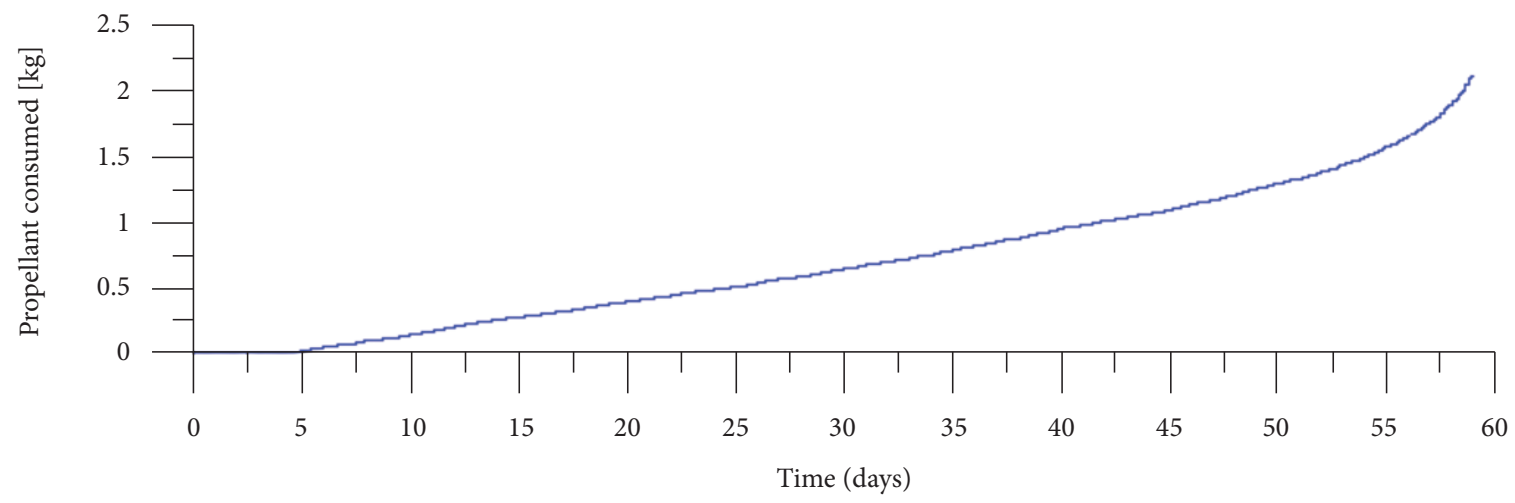

Figure 12. Aeroassisted situation: propellant necessary to correct the decay of perigee.

transfer, compared to $2.11 \mathrm{~kg}$ of fuel, necessary to the aeroassisted, plus PID control orbit maneuvering. Furthermore, it should be taken into account the propellant needed to enter to and exit from the transfer elliptical orbit. The propellant adopted was the liquid oxygen/liquid hydrogen, whose specific impulse is $460 \mathrm{~s}$.

Table 2 shows a comparison of propellant consumption and transfer time among Hohmann transfer, Bi-elliptic transfer and aeroassisted maneuver. It was considered the consumption of propellant to enter and to exit from the elliptical orbit transfer. The aeroassisted maneuver spent $160.92 \mathrm{~kg}$ of propellant, where $2.11 \mathrm{~kg}$ were used to correct the decay of perigee, and $158.81 \mathrm{~kg}$ to get in and out of the transfer orbit. The fuel economy of aeroassisted maneuver related on the transfer of Hohmann was approximately $116 \mathrm{~kg}$.

Table 2. Comparative table of propellant consumption and transfer time.

\begin{tabular}{|c|c|c|}
\hline Maneuvers & $\begin{array}{c}\text { Propellant } \\
\text { Consumption }[\mathbf{k g}]\end{array}$ & $\begin{array}{c}\text { Transfer time } \\
\text { [days] }\end{array}$ \\
\hline Hohmann & 276.62 & 0.22 \\
\hline Bi-elliptic & 361.25 & 1.48 \\
\hline Aeroassisted & 160.92 & 58.93 \\
\hline
\end{tabular}

The aeroassisted maneuver took 58.93 days to reach the final orbit, while the transfer of Hohmann and bi-elliptical, required far less time, 0.22 and 1.48 days respectively. However, it was considered, in computations, the ideal case for calculating the transfer time of propulsive maneuvers, but when thrust is small, due to thruster size, and the number of propulsive maneuvers to reach the final orbit is increased, the time to perform the maneuver also increases.

\section{CONCLUSIONS}

It was presented the simulation of an aeroassisted maneuver to transfer a vehicle from a GEO to a low orbit altitude using propulsive jets to correct the decay in perigee altitude and to correct deviations between the reference trajectory and the disturbed trajectory. It can be concluded that the control system met expectations and that it has maintained the residual error in state vector within acceptable limits.

The control propulsive jets is able to maintain the perigee altitude within reasonable limits $(115 \mathrm{~km} \pm 0.5 \mathrm{~km})$, avoiding the vehicle to suffer high thermal loads during the atmospheric path. This case can be compared to the mission of scientific FBM, in which there was a need to transfer the satellite from a GEO to a low orbit, by means of aeroassisted maneuvers. In general, the aeroassisted maneuvers were more advantageous in terms of fuel economy than the fully propulsive maneuvers. The closed loop control system was critical to the simulation success, without which it would not be possible to eliminate efficiently the residual errors in the trajectory. 


\section{REFERENCES}

Brezun, E., Bondivenne, G. and Kell, P., 2000, "Aerobraking design and study applied to CNES microsatellite product line", 5th International Symposium of Small Satellites Systems and Services, La Baule, France. Proceedings... Paris: CNES, 2000. pp. 673-680.

Franklin, G.F., Powell, J.D. and Workman, M.L., 1998, "Digital Control of dynamic systems", $3^{\text {rd }}$ Edition, Addison-Wesley Publishing Co., Massachusetts, USA

Furlan, B.M.P., 1998, "Several studies apply to the French-Brazilian mission", Instituto Nacional de Pesquisas Espaciais (INPE), São José dos Campos, Brazil (in Portuguese).

Gilmore, D.G., 1994, "Satellite thermal control handbook", $1^{\text {st }}$ Edition, The Aerospace Corporation Press, California, USA.

Guedes, U.T.V., 1997, "Dispersion analysis of the reentry trajectory over the landing point, using geocentric inertial and lateral maneuvers", Ph.D. in Space Mechanics and Control Thesis, Instituto Nacional de Pesquisas Espaciais (INPE), São José dos Campos, Brazil (in Portuguese).

Hemerly, E.M., 2000, "Controle por computador de sistemas dinâmicos", 2nd Edition, Edgard Blücher Ltda, São Paulo, Brazil.

Kuga, H.K., Rao, K.R. and Carrara, V., 2008, "Introduction to Orbital Mechanics" $2^{\text {nd }}$ Edition, Instituto Nacional de Pesquisas Espaciais (INPE), São José dos Campos, Brazil (in Portuguese).

Kumar, M. and Tewari, A., 2005, "Trajectory and attitude simulation for aerocapture and aerobraking", Jornal of Spacecraft and Rockets, Vol. 42, No. 4, pp. 684-693. doi: 10.2514/1.7117.

Regan, F.J. and Anandakrishnan, S.T., 1993, "Dynamics of atmosphere re-entry", $1^{\text {st }}$ Edition, American Institute of Aeronautics and Astronautics, Washington, DC, USA.

Rocco, E.M., 2006, "Tools for analysis and simulation of spacecraft trajectories in keplerian orbit" Bremen: Center of Applied Space Technology and Microgravity ZARM, University of Bremen, Germany.
Rocco, E.M., 2008, "Perturbed orbital motion with a PID control system for the trajectory", XIV Colóquio Brasileiro de Dinâmica Orbital, Águas de Lindóia, Brazil.

Rocco, E.M., 2009, "Earth albedo model evaluation and analysis of the trajectory deviation for some drag-free missions", Proceedings of the $8^{\text {th }}$ Brazilian Conference on Dynamics Control and Applications, Bauru, Brazil.

Rocco, E.M., 2010, "Evaluation of the terrestrial albedo applied to some scientific missions", Space Science Reviews, Vol. 151, No. 1-3, pp. 135-147. doi: 10.1007/s11214-009-9622-6, 2010.

Santos, W.G., 2011, "Simulação de manobras aeroassistidas de um veículo espacial controlado por placas aerodinâmicas reguláveis e sistema propulsivo", Dissertação de Mestrado em Mecânica Espacial e Controle, Instituto Nacional de Pesquisas Espaciais (INPE), São José dos Campos, Brazil, pp. 272.

Schulz, W., 2001, "Study of orbital transfers including aeroassisted maneuvers" Ph.D. in Space Mechanics and Control Thesis, Instituto Nacional de Pesquisas Espaciais (INPE), São José dos Campos, Brazil, pp. 178 (in Portuguese).

Theil, S. and Silas-Guilherme, M., 2005, "In-orbit calibration of dragfree satellites", Advances in Space Reseach, Vol. 36, pp. 504-514. doi: 10.1016/j.asr.2005.05.126.

Vinh, N.X., Busemann, A. and Culp, R.D., 1970, "Hypersonic and planetary entry flight mechanics" Elsevier, Amsterdam, Germany.

Vinh, N.X., 1981, "Optimal trajectories in atmospheric flight" Elsevier, Amsterdam, Germany.

Walberg, G.D., 1985, "A survey of aeroassisted orbit transfer", Journal of Spacecraft and Rockets, Vol. 22, No. 1, pp. 3-18. 